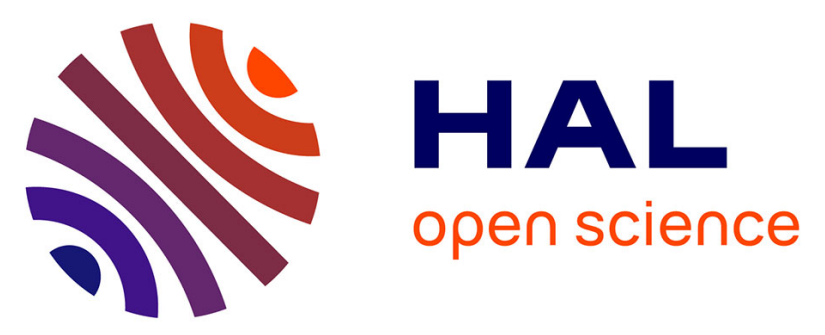

\title{
A Combined Experimental and Numerical Investigation of the Flow and Heat Transfer Inside a Turbine Vane Cooled by Jet Impingement
}

Emmanuel Laroche, Matthieu Fénot, Eva Dorignac, Jean-Jacques Vuillerme, Laurent-Emmanuel Brizzi, Juan Carlos Larroya

\section{To cite this version:}

Emmanuel Laroche, Matthieu Fénot, Eva Dorignac, Jean-Jacques Vuillerme, Laurent-Emmanuel Brizzi, et al.. A Combined Experimental and Numerical Investigation of the Flow and Heat Transfer Inside a Turbine Vane Cooled by Jet Impingement. Journal of Turbomachinery, 2017, 140 (3), pp.031002. 10.1115/1.4038411 . hal-01735695

\section{HAL Id: hal-01735695 \\ https://hal.science/hal-01735695}

Submitted on 16 Mar 2018

HAL is a multi-disciplinary open access archive for the deposit and dissemination of scientific research documents, whether they are published or not. The documents may come from teaching and research institutions in France or abroad, or from public or private research centers.
L'archive ouverte pluridisciplinaire HAL, est destinée au dépôt et à la diffusion de documents scientifiques de niveau recherche, publiés ou non, émanant des établissements d'enseignement et de recherche français ou étrangers, des laboratoires publics ou privés. 


\title{
A combined experimental and numerical investigation of the flow and heat transfer inside a turbine vane cooled by jet impingement
}

\author{
Emmanuel Laroche ${ }^{1}$ \\ ONERA, The French Aerospace Lab \\ F31055, Toulouse, France \\ emmanuel.laroche@onera.fr \\ Matthieu Fenot \\ PPRIME Institute \\ Chasseneuil Futuroscope, France \\ Eva Dorignac \\ PPRIME Institute \\ Chasseneuil Futuroscope, France \\ Jean-Jacques Vuillerme \\ PPRIME Institute \\ Chasseneuil Futuroscope, France \\ Laurent Emmanuel Brizzi \\ PPRIME Institute \\ Chasseneuil Futuroscope, France \\ Juan Carlos Larroya \\ Safran Aircraft Engines \\ Moissy Cramayel, France
}

\section{ABSTRACT}

The present study aims at characterizing the flow field and heat transfer for a schematic but realistic vane cooling scheme. Experimentally, both velocity and heat transfer measurements are conducted to provide a 
detailed database of the investigated configuration. From a numerical point of view, the configuration is investigated using isotropic as well as anisotropic Reynolds-Averaged Navier-Stokes (RANS) turbulence models. An hybrid RANS/LES technique is also considered to evaluate potential unsteady effects. Both experimental and numerical results show a very complex 3D flow. Air is not evenly distributed between the different injections, mainly because of a large recirculation flow. Due to the strong flow deviation at the hole inlet, the velocity distribution and the turbulence characteristics at the hole exit are far from fully developed profiles. The comparison between PIV measurements and numerical results shows a reasonable agreement. However, coming to heat transfer, all RANS models exhibit a major overestimation compared to IR thermography measurements. The Billard-Laurence model does not bring any improvement compared to a classical k- $\omega$ SST model. The hybrid RANS/LES simulation provides the best heat transfer estimation, exhibiting potential unsteady effects ignored by RANS models. Those conclusions are different from the ones usually obtained for a single fully developed impinging jet.

\section{INTRODUCTION}

In today's engines inlet turbine gas temperature largely exceeds blade material melting temperature. As a result, cooling techniques are essential to maintain blades at a reasonable temperature. A satisfactory understanding of these techniques is crucial to achieve optimum heat transfer while minimizing the coolant flow rate. With film cooling, jet impingement is one of the most frequently used techniques for turbine blade cooling. It is especially introduced where the thermal conditions are the most severe: the nozzle guide vane, the leading edge and midspan regions of the vanes. In spite of their apparent simplicity, impinging jets reveal a complex dynamic, which is responsible for an intensive heat transfer rate. To optimize this process, a detailed knowledge of the flow mechanisms (in particular in the near wall flow structures) and of 
the thermal interaction between the fluid and the wall is required. Consequently, many studies have been conducted on the visualization, qualification and comprehension of jet flow structures and heat transfer. Martin[1], Jambunathan et al.[2], Viskanta [3] and Zukerman and Lior[4] have reviewed a large panel of jet impingement studies. The most widely studied configuration is a single jet issuing from a long tube or from a contraction nozzle. For such "academic" configurations, an impinging jet can be divided into three zones: the free jet, the stagnation zone and the wall jet. The free jet is itself constituted of a potential core (low turbulent region) surrounded by a shear layer with roll-up vortices. Close to the wall, the jet enters the stagnation zone. In this zone, jet flow is turned radially outward. Mixing layer vortices are deflected and roll along the impinging plate. Resulting heat transfer has been measured and studied by many authors ([5-7]) with a maximum around the impinging point and then a decrease. Coming to the issue of multi-array impingement cooling, the numerous studies are summarized in a review paper by Weigand and Spring [8], investigating such effects as crossflow or jet/jet interaction. Earlier, Florschuetz et al provided correlations for uniform and staggered jet arrangements [9].

But such jets and heat transfer rates could be very different from those encountered in vane cooling systems principally because of the impinged plate curvature and of the injection flow feeding: impinging jets are typically generated with a thin perforated plate inserted into the vane and pressurized with air. Air is injected through the perforations and impinges on the vane inner surface. Very few studies have been conducted on such a jet ([10]) and none, to our knowledge, have taken into 
account all parameters encountered in a vane (injection feeding, multiple jets, curvature). The purpose of the present study is to investigate the flow and heat transfer for a large scale vane cooling scheme. Both flow and heat transfer have been measured experimentally and compared to numerical simulations. The chosen configuration corresponds to a global mass flow rate that provides a mean Reynolds number value of 10000 in each hole.

\section{EXPERIMENTAL SET-UP AND MEASUREMENTS}

\section{Experimental facility}

The experimental facility is shown in Figure 1. The air flow is supplied by a fan, and passes through a heat exchanger to control its temperature throughout the experiment (maintained equal to $20^{\circ} \mathrm{C}$ ). A valve regulates the global air flow rate and a venturi meter allows to measure the mass flow. The venturi meter and associated pressure converters had previously been calibrated over the mass flow rate range of the experiment (up to $60 \mathrm{~g} / \mathrm{s}$ ). The airflow goes through a divergent passage and enters the central cavity of the test section which is presented in Figure 2.

The test section is divided in two parts: the central cavity that feeds the different holes and the impingement plate which represents the blade wall. The central cavity is a rectangular channel, $400 \mathrm{~mm}$ large, $250 \mathrm{~mm}$ long and $20 \mathrm{~mm}$ high made of altuglas. A semi cylinder closes the channel on the leading side. Three rows of five D1=10mm diameter holes are drilled through upper and lower part (representing pressure and suction sides). A row of nine larger holes (D2 diameter equal to $1.25 \mathrm{D} 1=12.5 \mathrm{~mm}$ ) are 
made through its semi cylinder part. The injection plate thickness is equal to $10 \mathrm{~mm}$ for all the holes.

Two different impingement plates are used depending on the measurement technique. For velocity measurement, the impingement plate is made of altuglas to allow optical access. For heat transfer measurement, jets impinge on a $0.4 \mathrm{~mm}$ epoxyglass plate covered on the impinging side with a thin copper foil. The thickness of the copper foil is $35 \mu \mathrm{m}$ and it is engraved by a circuit that is linked to a DC supply and allows heating of the plate by Joule effect. The back of the impingement plate is painted in black to ensure high uniform emissivity $(\varepsilon=0.95)$ to allow a rigorous estimation of radiative heat fluxes and heat transfer measurements. An infrared camera (CEDIP titanium) measures the backward temperature of the plate. To cover the whole plate, 21 images are recorded. The junctions between them correspond to low emissivity marks which will be visualized later on the heat transfer distribution under the form of white disks.

\section{Jets injection mass flow measurement}

Only the global mass flow rate is measured and controlled through the valve and the venturi meter seen on Figure 1. However, due to the relative small size of the central cavity, the flow distribution is heterogeneous between the 39 holes. To estimate the ratio between the different injection holes, a specific experiment has been conducted. Considering that the impinged plate has no influence over the injection flow 
for an injection-to-plate distance superior to 1 injection diameter [11], the impinged plate was removed and 39 identical venturi meters were added at the exit of each hole, allowing us to measure injection mass flow rate individually.

\section{Velocity measurement}

Particle image velocimetry was used to measure and calculate mean and RMS velocity fields. Flow seeding was achieved with a smoke atomizer producing water and glycerin particles which mean diameter is inferior to $1 \mu \mathrm{m}$. Those particles were injected directly into the fan. The flow was illuminated by a Yag pulsed Laser. Resulting light sheet thickness is inferior to $1.5 \mathrm{~mm}$. Images were acquired with a $1008 \times 1014 \mathrm{px}^{2}$ HiSense camera with a sampling frequency of $4.5 \mathrm{~Hz}$ for all measurements.

To ensure accurate statistics, we record a total number of velocity fields superior to 1000 for each measurement. Velocities were estimated using Davis software. A three step adaptive cross-correlation was used (initial pass $64 \times 64$, final pass $32 \times 32$ doubled, $50 \%$ overlap). Validation steps are carried out in an effort to eliminate erroneous velocity vectors: only vectors with a signal/noise ratio of 1.5 are validated and 500 validated vectors are needed to take a result into account.

To understand the very complex topology of the flow field, velocity measurements have been performed in different planes presented in Figure 3 (named (A) to (D)).

\section{Heat transfer measurement}


The method used to determine the heat transfer coefficient has already been presented in various papers ([6-10]). Considering the Newton's law of cooling:

$$
T_{w}=\frac{\varphi_{\text {conv }}}{h}+T_{r e f}
$$

With $\varphi_{\text {conv }}$, the convective heat flux density on the impinged side, $T_{w}$, the wall temperature and $\mathrm{T}_{\text {ref, }}$ the reference temperature. The method consists in prescribing different convective heat flux densities $\varphi_{\text {conv }}$ and in measuring the wall temperature $T_{w}$ at a given location of the impinged plate for each. Then, $1 / \mathrm{h}$ is identified as the slope and $T_{\text {ref }}$ as the $y$-intercept of a straight line linking each couple $\left(\varphi_{\text {conv }}, T_{w}\right)$ as seen in Figure 4. In practical terms, $\varphi_{\text {conv }}$ is prescribed using the copper circuit described above. A uniform electrical flux density is produced by Joule effect. Radiative losses on both sides and convective losses on the back side (opposite the impinged side) are calculated and deduced from the electrical flux to determine $\varphi_{\text {conv }}$. The sum of those losses is less than $15 \%$ of electrical heat flux. After thermal equilibrium is reached, temperature is recorded on the back side of the plate using an infrared camera. By repeating this procedure four times for each position with different electrical flux densities (from $500 \mathrm{~W} / \mathrm{m}^{2}$ to $2000 \mathrm{~W} / \mathrm{m}^{2}$ ), we can deduce the cartographies of local convective heat transfer coefficient $h$ and reference temperature Tref. Uncertainties were calculated using the statistical approach based on Coleman and Steele [12]. Taking into account errors due to ambient and injection temperature to electrical, radiative and convective fluxes, and to emissivities, uncertainty for the Nusselt number values is not higher than $10 \%$ while overall uncertainty for $\mathrm{T}_{\text {ref. }}$ is less than $1^{\circ} \mathrm{C}$ ( $95 \%$ confidence level for both). 


\section{NUMERICAL MODEL}

\section{Reynolds Averaged Navier-Stokes (RANS) modelling}

The mesh was generated using Centaur ${ }^{\circledR}$ meshing software. This mesh is a hybrid one, made of prisms at the walls, tetraedra far from the wall and a minor number of pyramids. Two grids were generated to check mesh convergence issues. The first one is made of approximately $13 \mathrm{M}$ cells, the second one about $55 \mathrm{M}$ cells (Figure 5). One of the main difference is the level of mesh discretization in the holes. For the coarse mesh, around 15 cells are present along one diameter, whereas for the fine mesh more than 30 cells discretize the hole dimension. The calculation is carried out using ONERA's in house CEDRE $^{\circledR}$ multi-physics platform. This platform was developed for both research and industrial applications, in the field of energetics and propulsion. The software architecture follows a multi-domain, multi-solver approach and accepts any general unstructured grid. Each physical system is treated by a dedicated solver: gas phase, dispersed phase, thermal fields in solids and radiation. Here, only the Navier-Stokes solver called CHARME was used. Details about the CEDRE platform can be found in [13].

Concerning the choice of RANS models, the k- $\omega$ SST model is the industrial reference adopted here. It is described in [14] and is seen in [4] as the most adapted model for impinging flows in the framework of 'classical' turbulence RANS closures. The $\mathrm{k}-\varepsilon$ Billard-Laurence model is described in [15]. This model was selected here as the most recent evolution of the former $v^{2}-f$ model. The $v^{2}-f$ model, initially developed by Durbin [16] was shown to give a particularly good estimation of the heat transfer rate 
generated by a single cold jet impinging on an heated plate [17]. This conclusion was confirmed later by different authors using more modern versions of the $v^{2}-f$ models, based on $\phi=v^{2} / k$, instead of $v^{2}$, to improve the robustness of the model. This particularly good prediction is attributed to the original wall treatment based on the resolution of an elliptic equation derived from the pressure fluctuation Poisson equation.

The choice of the DRSM-SSG model is not driven by the impinging zones, but more by the strongly complex 3D, fully turbulent character of the flowfield, with strong off-equilibrium effects. In particular, severe curvature effects are expected in the region going from the main feeding to the injection holes. The VALM model described in [18] appears as an intermediate model between the isotropic k- $\omega$ SST and Billard-Laurence models and the DRSM SSG model. It relies on a complex explicit algebraic formulation of Reynolds Stresses and turbulent heat fluxes. In particular Reynolds stresses and turbulent heat fluxes are not aligned with the strain rate and temperature gradient respectively The damping to the wall is inspired from the elliptic blending approach to avoid ad-hoc damping functions.

The inlet mass flow rate is $60 \mathrm{~g} / \mathrm{s}$, with a total temperature of $296 \mathrm{~K}$. The turbulent scales at the injection were not measured and therefore some values had to be assumed. For the $k-\omega$ SST model, $k=0.5 \mathrm{~m}^{2} . \mathrm{s}^{-}{ }^{2}, \omega=500 \mathrm{~s}^{-1}$. For other models, a straightforward transformation was applied when necessary. For the Billard Laurence model, an inlet value of 0.4 was adopted for $\phi$, which corresponds to an average value in channel calculation. Concerning elliptic blending formulations, $\alpha$ was prescribed to 1 at the inlet, which is the value far from the wall. An atmospheric pressure was specified at 
the outlet. Walls were considered as adiabatic, except for the heated parts, where a uniform heat flux density of $1600 \mathrm{~W} / \mathrm{m} 2$ was applied. This heat flux level does not correspond to the real heating, but the comparison on $\mathrm{h}$ is not hindered by this assumption.

The interpolation scheme is of order 2 in space, with a HLLC scheme for the convective flux. A Van Leer Slope limiter is used to guarantee the absence of space oscillations. The time integration is implicit, with an Euler-Backward scheme of order 1 in time for RANS calculation. The calculation is converged using a CFL based local time, with an extra limitation guaranteeing the absence of strong variations from an iteration to the next one. The residuals are diminished by 2 to 3 orders of magnitude after 20000 iterations or less depending on the models. Considering heat fluxes, the results on the coarse and fine grids do not differ by more than $4 \%$ locally and 2 to $3 \%$ on the average for the k- $\omega$ SST. The results on the coarse mesh were therefore considered as reasonably good and advanced models were evaluated on the coarse mesh. The $\mathrm{y}^{+}$at the wall was under 0.5 for all calculations, which was judged appropriate for wall heat transfer resolution.

\section{Zonal detached eddy simulation}

The Zonal Detached Eddy Simulation is a hybrid RANS-LES method introduced by Deck [19] and recently improved and generalized in [20]. This approach aims at treating the attached boundary layers using URANS modeling whereas the separated zones are treated using LES models. The ZDES approach, highly inspired by the DES97 and DDES methods of Spalart ([21][22]), switches from a URANS model to a LES sub-grid model by 
modifying the turbulent length scale which plays an essential role in the destruction term of the eddy viscosity. While in the original DES97 method, relying on the SpalartAllmaras RANS model, the wall distance is changed to modify the destruction term of the eddy viscosity $v_{t}$ transport equation, Strelets [23] suggested a modification to extend the use of the DES97 model to $k-\omega$ based RANS models. The destruction term is modified such that the eddy viscosity $v_{t}$ can depart from its normal RANS form to a LESlike one. Details on the ZDES algorithm embedded in CEDRE software can be found in $[24]$.

The ZDES calculation starts from a k- $\omega$ SST solution. To allow the destabilization of this initial estimation, the mesh requirements are close to the ones of a LES simulation far from the wall. The dissipation estimation being based on the cell size, the grid has to be sufficiently fine in critical regions. The initial attempt to restart the calculation from the RANS fine solution was not satisfactory, and a new refined mesh was generated, with a characteristic size of $0.25 \mathrm{~mm}$ in the hole region. The hole inlet/exit regions are also refined with a characteristic size of $0.5 \mathrm{~mm}$, to allow the destabilization of the flow. The characteristics of the mesh can be seen in Figure 6 . The mesh size being $66.4 \mathrm{M}$, no other refined mesh was generated to assess mesh convergence studies. The initial solution is interpolated from the RANS fine mesh to this new mesh. A time step of $2 \cdot 10^{-6} \mathrm{~s}$ is adopted, which corresponds to a convective CFL number of 2 to 3 . After the initial transition from the RANS regime to a fully unsteady one, 6 runs of 4000 iterations are run, to converge the average solution and the turbulent statistics, which represents a physical duration of approximately $0.05 \mathrm{~s}$. 
An instantaneous distribution of the unsteady obtained solution can be seen in Figure 7. The flow is fully turbulent with large scale vortices and a hole dependent pattern. Concerning the hybrid ZDES treatment, the distinction between the URANS and the LES treated zones can be seen using the $f_{\text {ddes }}$ function. When this function is close to 0 , the zone is treated in a RANS mode, whereas when close to 1 , the simulation is in a LES mode. Figure 8 confirms that the URANS treatment is applied to near-wall zones, whereas all other zones are resolved on a LES basis, which explains the fully unsteady behavior captured in Figure 7. For simplicity reasons, only time-averaged results will be presented from now on.

\section{AERODYNAMIC RESULTS}

Throughout this document, the coordinates $(X, Y, Z)$ denote respectively the Cartesian coordinates as presented in Figure 3. The axis originates at the exit of the central hole on the leading edge (fifth hole of row1), on its axis. The fluid flow will be presented comparing experimental measurements to their numerical counterparts, being either RANS or ZDES results. The topology of the flow is not considerably modified by the RANS model used. The results provided by RANS and ZDES approaches are also qualitatively similar. On the contrary, the heat transfer level is strongly dependent on the model. For the RANS simulation, the flow topology will therefore be described based on the results obtained with the k- $\omega$ SST model. The flow topology can be visualized on Figure 9. The air feeds the central cavity through the lateral inlet. Due to the pressure difference, this air will go through the different holes and impinge on the opposing walls. The available mass flow rate diminishes along the central cavity, corresponding to 
a velocity decrease. The velocity profiles inside the different holes appear to be strongly heterogeneous as shown in Figure 10. This figure presents mass flow rates measured in each hole of the leading edge and on the pressure side of the vane. As pressure and suction sides are geometrically symmetric, their mass flow rate distributions are nearly identical (consequently, suction side distribution is not presented here). The leading edge row (row1) is globally better supplied (1.22 time higher than the three other rows on average) due to the greater injection diameters ( $D 2=1.25 \mathrm{D} 1)$. The distribution of the mass flow rate for each row is globally the same. In particular, lowest mas flow rates are recorded for $Z=80 \mathrm{~mm}$ for every rows. This is due to a large recirculation zone in the central cavity near the penultimate hole of the fourth row. This recirculation is due to the main flow that impinges the central cavity right wall $(X=200 \mathrm{~mm})$ and is turned to the back of the cavity.

As a matter of fact, the air comes from the central cavity horizontally and is strongly deviated to go through the holes. For the leading edge holes, this results in a concentration of the mass flow rate in the downstream part of the hole as seen on Figure 11-bottom. The upstream part of the perforation is characterized by a recirculation zone, with low velocity magnitudes. On the pressure side of the vane, the hole flows are even more complex. For example, Figure 11 presents velocity fields resulting from PIV measurements of plane (C) and (D) (see Figure 3 for the plane definition). Those fields show the flow around the third injection of the second row of injection (on the pressure side). The upper velocity field shows clearly that most of flow is injected through the side of the injection hole with a small recirculation zone at the 
center. Moreover, velocity values are higher and the width of the jet is greater for the low $\mathrm{X}$ side of the injection. In the orthogonal plane (lower velocity fields of Figure 11), flow is injected through the downstream part of the hole (upper $Z$ axis). Consequently, the injection flow presents a crescent shape with a mass flow rate concentrated over a quarter of the injection hole (lower $\mathrm{X}$, upper $\mathrm{Z}$ axis). Those characteristics of the flow differ from the fully developed profiles considered in single jet studies and mostly often adopted for code validation. The strong acceleration and turning of the flow at the hole inlet also correspond to a far from equilibrium situation from a turbulent point of view, and one can expect a bad prediction of the turbulent profiles in that region. On Figure 12 , which represents RMS velocity fields, we can notice some major differences between jets on pressure side and more academic jets (issuing from a long tube or a contraction nozzle): in plane $\mathrm{C}$ the highest levels of turbulence are not recorded in the shear layer but in the jet. Moreover, RMS values tend to be lower away from the injection which is exactly the opposite of an academic jet.

For the leading edge, the comparison between PIV acquisitions and CEDRE results is showed in Figure 13 and Figure 14. The location of the slice is detailed in Figure 3. The analysis of Figure 13 reveals a minimum velocity at the hole center, and a maximum one near the edges of the holes. This result, however surprising it may appear, is explained by the strong deviation of the flow at the hole inlet. This deviation explains also the increase of mean velocity values in the central part of the jet $(2 \mathrm{~mm}<\mathrm{X}<20 \mathrm{~mm})$ : it is due to the flow injected through the downstream part of the hole going upstream. For $X>20 \mathrm{~mm}$, the velocity mean distribution of the jet become similar 
to an academic jet one even if RMS values visible in Figure 14 (top) are still very different. Finally, the impinged plate curvature has also consequences on the jet flow, in particular on the two large recirculations situated on both sides of the jet (lowest velocity values in Figure 13). The 3D flow is also visible in Figure 15, presenting the velocity fields in a plane between two injections. The flow is relatively complex with two contra-rotating recirculation cells located at $(X=30 \mathrm{~mm} ; Y=-108 \mathrm{~mm})$ and $(X=40 \mathrm{~mm}$; $\mathrm{Y}=12 \mathrm{~mm}$ ). Moreover, high velocities along the curved plate show that a large part of the flow moves along the $Z$ axis. As stated before, the flow velocity is maximum in the downstream part of the hole and a slice going through the center of the hole will exhibit high levels of velocity near the walls and a minimum far from the wall, as confirmed by Figure 16. The analysis of Figure 16 also reveals secondary kidney-shaped vortices inside the holes, due to the strong deviation of the flow at the hole inlet. Those secondary vortices will gradually bring the high velocity air of the downstream part of the hole to the upstream part along the wall. Coming to the comparison on velocity magnitudes, Figure 13 reveals a good agreement between experiment and calculation. The main difference appears in the jet penetration, the measured jet being less diffused than the simulated one. The analysis of the RMS distributions provided in Figure 14 confirms that the turbulent fluctuations are qualitatively in good agreement with the measurements, but underestimate the turbulent fluctuations, in particular in the mixing layer regions.

This underestimation of the turbulent fluctuations leads to a lower level of turbulent mixing at the hole exit, leading to a stronger penetration of the jet in the simulation. Coming to ZDES results, the agreement between ZDES and experiment is 
qualitatively and quantitatively good. Compared to RANS modelling the penetration of the jet is less intense and closer to PIV measurements. This can be traced back to a better description of the unsteady structures issued from the holes.

Those unsteady structures contain a major part of the turbulent energy that cannot be represented by RANS modelling. This conclusion is also obtained on RMS quantities, which exhibit more intense levels, corresponding to higher levels of turbulent mixing at the exit of the holes

\section{HEAT TRANSFER RESULTS}

For experimental results, the heat transfer coefficient and the reference temperature are evaluated from a linear regression (see Heat transfer measurement above). Four different flux densities (from $500 \mathrm{~W} / \mathrm{m}^{2}$ to $2000 \mathrm{~W} / \mathrm{m}^{2}$ ) are prescribed. The air temperature injected into the test section is maintained equal to $296 \mathrm{~K}$. Consequently, the reference temperature measured on the impinged plate is nearly constant and equal to $296 \mathrm{~K}$ For the RANS modelling, the heat transfer coefficient is derived from the formula:

$$
h=1600 . /(\text { Tw }- \text { Tref })
$$

where $T_{\text {ref }}$ is taken to the inlet total temperature of $296 \mathrm{~K}$.

The experimental distribution is showed in Figure 17. Results obtained with the k- $\omega$ SST and Billard Laurence models are also provided. For formatting reasons, the distributions obtained with the VALM and DRSM models are not presented here. The experimental heat transfer distribution exhibits local maxima due to the impact of the 
cooling jets. The maximum value is approximately around $200 \mathrm{~W} / \mathrm{m}^{2} / \mathrm{K}$ in the impingement regions on the pressure and suction sides, and around $140 \mathrm{~W} / \mathrm{m}^{2} / \mathrm{K}$ in the leading edge region. The heat transfer distribution also depends on the column considered and can be directly related to the mass flow rate going through the hole. In particular, $\mathrm{h}$ values in front of the fourth hole of row 4 are clearly lower due to the small mass flow rate injected (see Figure 8). One noticeable exception is the leading edge region which presents lower maximum $\mathrm{h}$ values than pressure and suction sides with globally higher mass flow rate injected in the holes. This could be explained by the larger injection-to-plate distance on the leading edge and by the rapid velocity decrease noted on Figure 11 (top). Due to the specific injection flow, the jet flow velocity rapidly decreases causing the drop of heat transfer rate. Another important characteristic of the leading edge heat transfer rate is its relative homogeneity due to the flow movement along the $Z$ axis and the relative small jet-to-jet spacing. On the pressure side, due to the larger jet-to-jet spacing and smaller injection to plate distance, impinging areas are well defined. It is to be noticed that $\mathrm{h}$ maxima are not always situated in front of their respective injection (represented by black dashed circles) and their relative position depend on the injection. This is particularly visible for injections situated on the right side of the impinged plate. This gap between axis injection and $h$ maxima is the consequence of the non-axisymmetric distribution of the flow in the holes. 
Coming to simulations all models strongly overestimate the heat transfer level in the impingement regions. A maximum value around $400 \mathrm{~W} / \mathrm{m}^{2} / \mathrm{K}$ is predicted by all models, corresponding to a $100 \%$ discrepancy compared to measured value. However, the topology of the heat transfer distribution is in qualitative good agreement with the experimental one in terms of peak location. The lower values obtained at the second column are also reproduced by the simulation. This fairly good qualitative agreement can be traced back to a topologically correct prediction of the fluid flow in the cavity. The poor prediction obtained in terms of heat transfer can probably be attributed to a unsatisfactory damping of the turbulence to the wall. The comparison between the results obtained with the different RANS models can be visualized in Figure 18, where the heat transfer coefficient profile along the second column of holes is plotted. All models exhibit the aforementioned overestimation in the pressure/suction side region, that is for small $\mathrm{H} / \mathrm{D}$ ratio. The behavior at the leading edge is somewhat different The Billard-Laurence model offers the poorest prediction with an estimated htc of 350 $\mathrm{W} / \mathrm{m}^{2} / \mathrm{K}$ instead of $150 \mathrm{~W} / \mathrm{m}^{2} / \mathrm{k}$. The best predictions are brought by the $\mathrm{k}-\omega \mathrm{SST}$ and DRSM models. Once again the peaks locations, and the overall topology of the htc distribution are in good agreement with the measured values.

The poor performance of all RANS models is contrary to what is expected based on a literature survey. In particular, the poor behavior of the Billard-Laurence model is still to be explained. The most probable explanation relies on the turbulence profiles at the hole exit, which are from those usually adopted in the single jet configuration. As a matter of fact, in the single jet configuration, the injected profiles are those of a fully 
developed channel, with lower turbulent maxima located near the walls. The central part of the turbulent profile (which is the one influencing the maximum heat transfer level), corresponds to a fairly low level of turbulent viscosity. The heat transfer obtained using the ZDES approach can be seen on Figure 18. For comparison purposes, the experimental and RANS results are presented on the same figure. The heat transfer levels are in a better agreement with the measured heat transfer. On the pressure and suction sides, the maxima are around $250 \mathrm{w} / \mathrm{m}^{2} / \mathrm{K}$ to be compared instead of 200 $\mathrm{w} / \mathrm{m}^{2} / \mathrm{K}$. This $20 \%$ discrepancy has to be compared with the one for RANS models, which was around $100 \%$. At the leading edge, the heat levels are underestimated by the simulation by $30 \%$. A possible explanation relies in a mesh still too coarse. The distance between the holes and the impinging plate being more important at the leading edge, the numerical dissipation operates on a larger region, leading to an overestimated dissipation of the turbulent structures at the jet boundaries. As already stated, the mesh discretization could not be improved due to CPU time constraints, and this hypothesis could not be checked out.

\section{CONCLUSIONS}

The present study investigates the flow field and heat transfer inside a simplified, however representative, cooling scheme of a turbine vane. Detailed velocity measurements are obtained through the use of PIV measurements whereas heat transfer cartographies are detailed using IR acquisitions. The flow topology is complex with a strongly heterogeneous mass flow rate distribution between the holes, and noticeable heat transfer maxima in impinging regions. RANS and ZDES simulations were 
conducted on this configuration. The qualitative agreement between PIV and simulation is reasonable for fluid flow results, the RANS simulations overestimating the penetration of the jets in the cooled cavity. The ZDES approach offers a better prediction of the turbulent mixing of the jets. As a consequence, the prediction of heat transfer is acceptable with ZDES, whereas a $100 \%$ overestimation is obtained with RANS approaches, even with models showing good agreement with measurement on simpler configurations.

\section{ACKNOWLEDGMENT}

The authors acknowledge the financial support of French Direction Generale de I'Aviation Civile (DGAC) in the framework of Research Programs ARCAE and AETHER. 


\section{NOMENCLATURE}

D1

D2

h

$X, Y, Z$

$\operatorname{Re}$

$\mathrm{T}_{\text {ref }}$

$\mathrm{T}_{\mathrm{w}}$

$u, v, w$

$\mathrm{U}_{\mathrm{RMS}}, \mathrm{v}_{\mathrm{RMS}}, \mathrm{W}_{\mathrm{RMS}}$

Greek symbols

$\varepsilon_{\mathrm{w}}$

$\lambda_{\text {air }}$

$\lambda_{\mathrm{w}}$

$\mu_{\text {air }}$

$\rho_{\text {air }}$

$\varphi_{\text {conv }}$
Jet Diameter of pressure and suction sides holes

m

Jet Diameter of leading edge holes (=1.25 D1)

m

Heat transfer coefficient on impinged side of the impinged $\mathrm{Wm}^{-2} \mathrm{~K}^{-1}$

plate

Cartesian coordinates

m

Injection Reynolds number $=\rho \mathrm{uD} / \mu$

Adiabatic wall temperature

K

Impinging side wall temperature

K

Mean velocities in the cartesian system

$\mathrm{ms}^{-1}$

Root mean square velocities in the cylindrical system

$\mathrm{ms}^{-1}$
Impinged plate emissivity

Air thermal conductivity

Impinged plate thermal conductivity

Air dynamic viscosity

Air density

Convective heat flux density on the impinged side
$\mathrm{Wm}^{-1} \mathrm{~K}^{-1}$

$\mathrm{Wm}^{-1} \mathrm{~K}^{-1}$

$\mathrm{Nsm}^{-2}$

$\mathrm{kgm}^{-3}$

$\mathrm{Wm}^{-2}$ 


\section{REFERENCES}

[1] Martin, H., 1977, "Heat and Mass Transfer between Impinging Gas Jets and Solid Surfaces," Advances in Heat Transfer, vol. 4, pp. 1-60.

[2] Jambunathan, K., Lai, E., Moss, M. A. and Button, B. L., 1992, "A review of heat transfer data for single circular jet impingement," International journal of heat and fluid flow, vol. 13, no. 2, pp. 106-115.

[3] Viskanta R., 1993, "Heat transfer to impinging isothermal gas and flame jets," Experimental thermal and fluid science, vol. 6, no. 2, pp. 111-134.

[4] Zuckerman, N. and Lior, N., 2006, "Jet impingement heat transfer:physics, correlations, and numerical modeling," Advances in Heat Transfer, vol. 39, pp. 565-631.

[5] Goldstein, R. and Behbahani, A., 1982, "Impingement of a circular jet with and without cross flow," International Journal of Heat Mass Transfer , vol. 25, pp. 13771382.

[6] Roux, S., Fénot, M., Lalizel, G., Brizzi, L. and Dorignac, E., 2011, “Experimental investigation of the flow and heat transfer of an impinging jet under acoustic excitation," International Journal of Heat and Mass Transfer, vol. 54, no. 15-16, pp. 3277-3290, 2011.

[7] Baughn, J. and Shimizu, S., 1989, “Heat transfer measurements from a surface with uniform heat flux and an impinging jet," Journal of Heat Transfer, vol. 111, no. 4, pp. 1096-1098.

[8] Weigand, B., and Spring, S., 2011, “Multiple Jet Impingement-A Review,"Heat Transfer Res., 42(2), pp. 101-142.

[9] Florschuetz, L. W., Truman, C. R., and Metzger, D. E., 1981, "Streamwise Flow and Heat Transfer Distributions for Jet Array Impingement with Crossflow," ASME J. Heat Transfer, 103(2), pp. 337-342.

[10] Fenot, M. and Dorignac, E., 2016, "Heat transfer and flow structure of an impinging jet with upstream flow," International Journal of Thermal Sciences, vol. 109, pp. 386400.

[11] Liu ,T., Sullivan, J.P.,1996, "Heat transfer and flow structures in an excited circular impinging jet," International Journal of Heat and Mass Transfer, vol. 39, issue 17, pp. 3695-3706. 
[12] Coleman, H.W., and Steele W. G., 1999, "Experimentation and uncertainty analysis for engineers," Chichester, United Kingdom: Wiley-Interscience.

[13] Refloch, A., Courbet, B., Murrone, A., Villedieu, P., Laurent, C., Gilbank, P., Troyes, J., Tessé, L., Chaineray, G., Dargaud, J.B., Quémerais, E. \& Vuillot, F., 2011, “CEDRE software," Aerospace Lab J. n², 2011.

[14] Menter, F. R., 1994, "Two-Equation Eddy-Viscosity Turbulence Models for Engineering Applications," AIAA Journal, vol. 32, no. 8, pp. 1598-1605.

[15] Billard, F., Laurence, D., 2011, “A robust $k-\varepsilon$, v2/k elliptic blending turbulence model applied to near-wall, separated and buoyant flows," International journal of Heat and Fluid Flow, vol. 33, issue 1, pp 45-58, 2011.

[16] Durbin P., 1991, "Near-wall closure modelling without damping functions," Theor. Comput. Fluid Dyn., vol. 3, issue 1, pp. 1-13.

[17] Benhia, M., Parneix, S., Durbin, P.A., 1998, "Prediction of heat transfer in an axisymmetric turbulent jet on a flat plate," Int. J. Heat Mass Transfer, 41, 1845-1855.

[18] Vanpouille, D., Aupoix, B., Laroche, E., 2015, "Development of an explicit algebraic turbulence model for buoyant flows -Part 2: Model development and validation," International Journal of Heat and Fluid Flow, Vol 53, pp 195-209.

[19] Deck, S., 2005, "Zonal-detached-eddy simulation of the flow around a high-lift configuration," AIAA Journal, vol. 43, No 11, pp 2372-2384.

[20] S. Deck, 2012, “Recent Improvements of the Zonal Detached Eddy Simulation (ZDES) formulation, Theoretical and Computational Fluid Dynamics," vol 26, no. 6, pp 523-550.

[21] Spalart, P., Jou, W., Strelets, M., and Allmaras, S.,1997," Comments on the feasibility of les for wings, and on a hybrid rans/les approach," 1rst International Conf. on LES/DNS.

[22] Spalart, P., Deck, S., Shur, M., Squires, K., Strelets, M. K., and Travin, A.,2006, "A new version of detached-eddy simulation, resistant to ambiguous grid densities," Theoretical and computational fluid dynamics, vol 20, pp180-195.

[23] Strelets, M., 2001, "Detached eddy simulation of massively separated flows," AIAA 39 th Aerospace Sciences Meeting and Exhibit, Reno, NV.

[24] Arroyo-Callejo, G., Laroche, E., Millan, P., Leglaye, F., and Chedevergne, F., 2016, "Numerical Investigation of Compound Angle Effusion Cooling Using Differential 
Reynolds Stress Model and Zonal Detached Eddy Simulation Approaches," J. Turbomach 138(10). 


\section{Figure Captions List}

Fig. $1 \quad$ Experimental apparatus

Fig. 2 Test section

Fig. $3 \quad$ PIV measurements planes

Fig. $4 \quad$ Heat transfer determination principle

Fig. $5 \quad$ Fine mesh overview

Fig. $6 \quad$ Mesh overview for ZDES modelling

Fig. 7 ZDES Velocity magnitude overview

Fig. $8 \quad F_{\text {ddes }}$ function distribution

Fig. 9 Velocity magnitude in a slice going through row 2 (CEDRE k- $\omega$ SST)

Fig. $10 \quad$ Mass flow rate distribution

Fig. 11 Velocity Magnitude Distribution, PIV (top: plane (C), bottom plane (D))

Fig. 12 Velocity RMS Distribution, PIV (top : plane (C), bottom plane (D))

Fig. 13 Velocity Magnitude Distribution, plane (A) (top : PIV, middle CEDRE RANS, bottom CEDRE, ZDES )

Fig. 14 Axial velocity RMS Distribution, plane (A) (top : PIV, bottom CEDRE k- $\omega$ SST)

Fig. 15 Velocity Magnitude Distribution, plane (B), PIV

Fig. 16 Velocity Distribution/Streamlines colored by velocity inside the hole 
Fig. 17 Heat transfer coefficient distribution (top: Exp., Middle, k- $\omega$ SST; bottom Billard-Laurence)

Fig. 18 Heat transfer coefficient profile along the second column of holes 


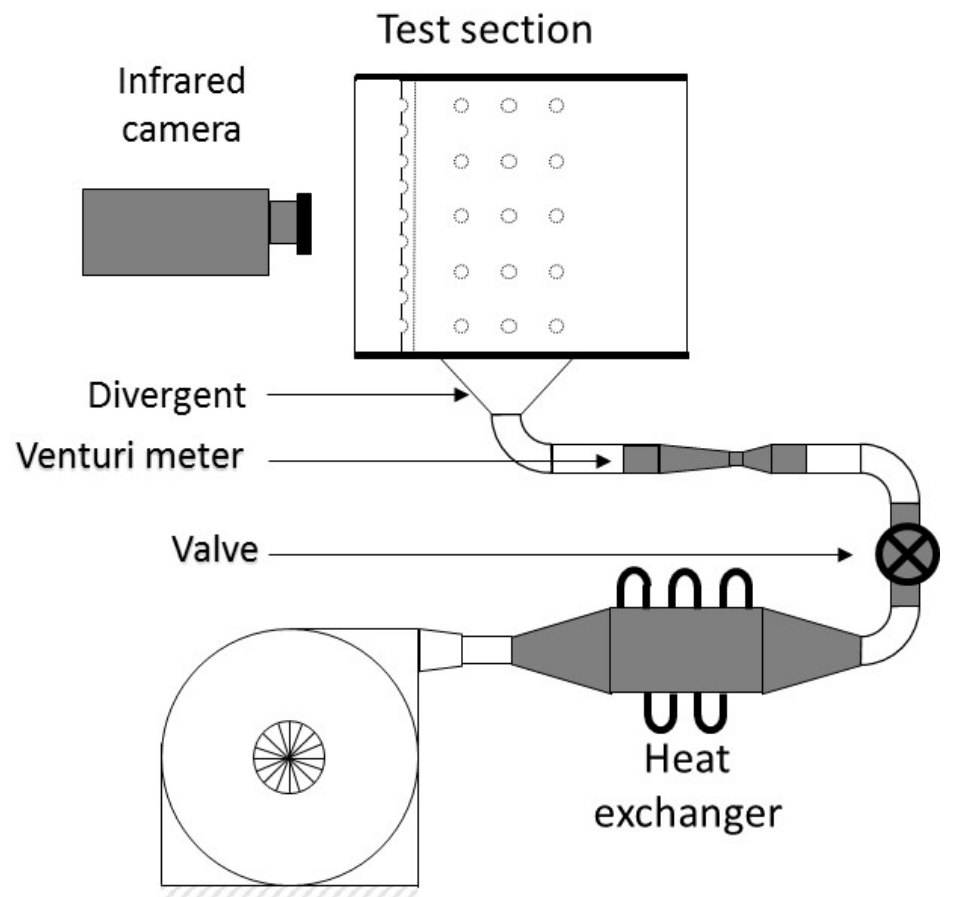

Figure 1. Experimental apparatus 
Impinged plate
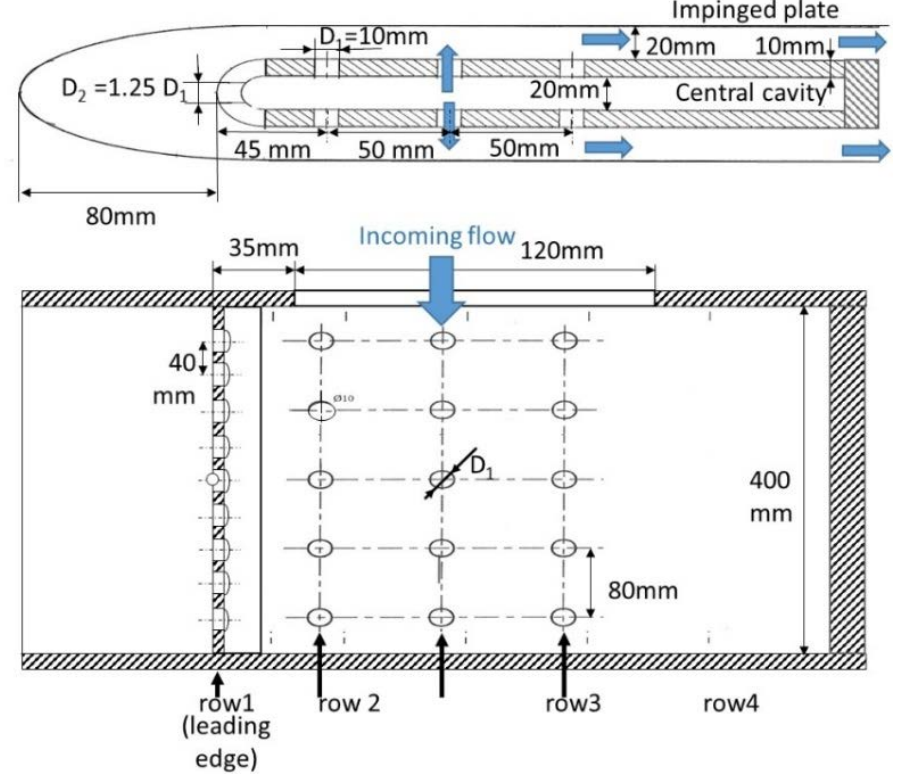

Figure 2. Test section 


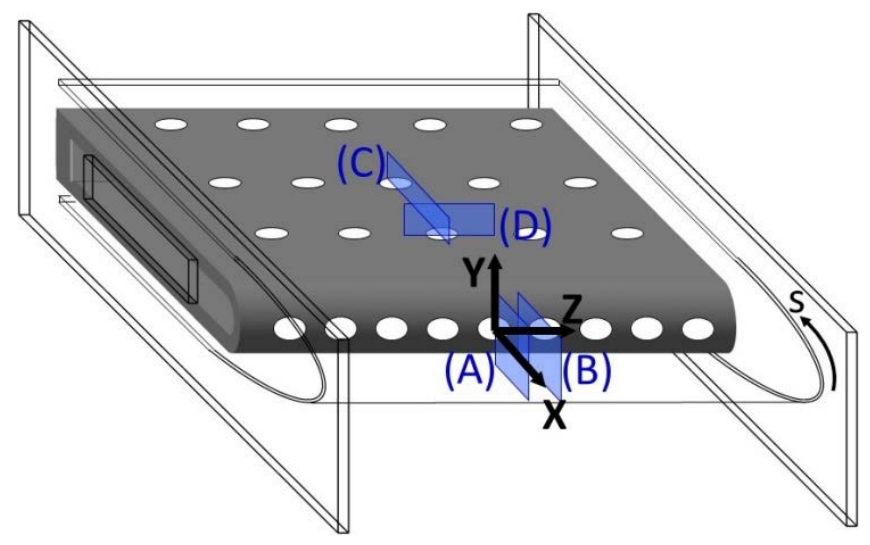

Figure 3. PIV measurements planes 


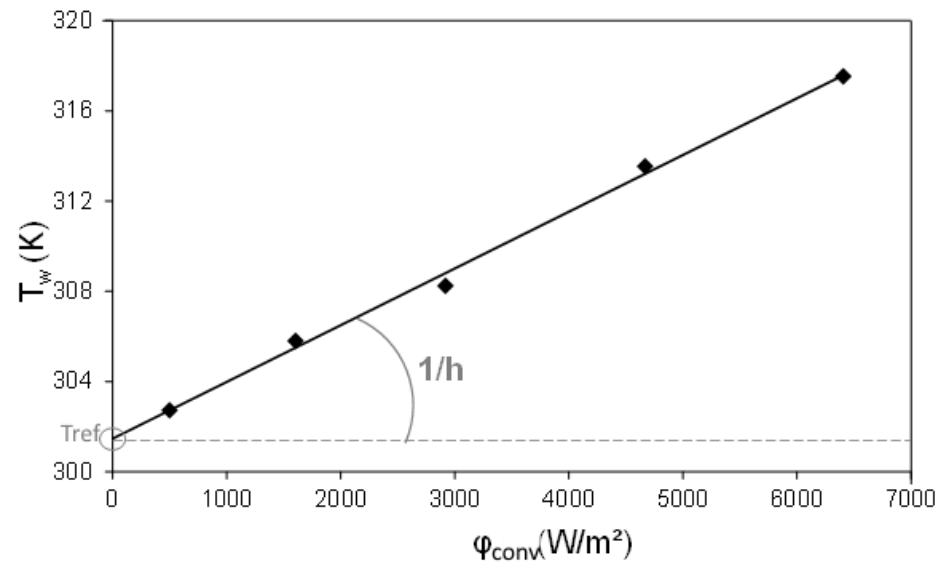

Figure 4. Heat transfer determination principle 


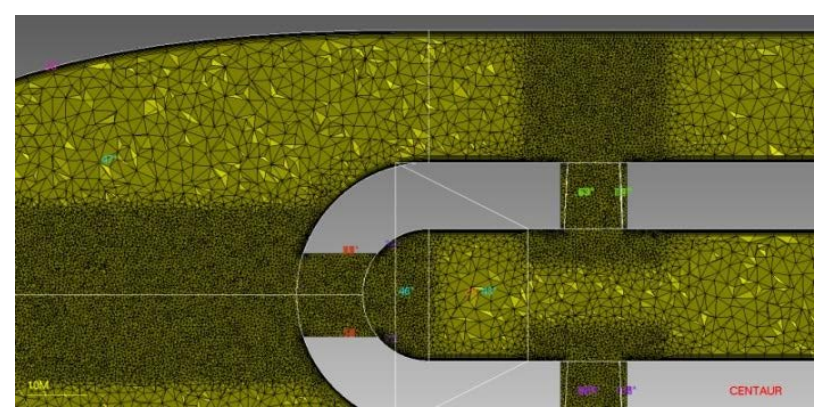

Figure 5. Fine mesh overview 


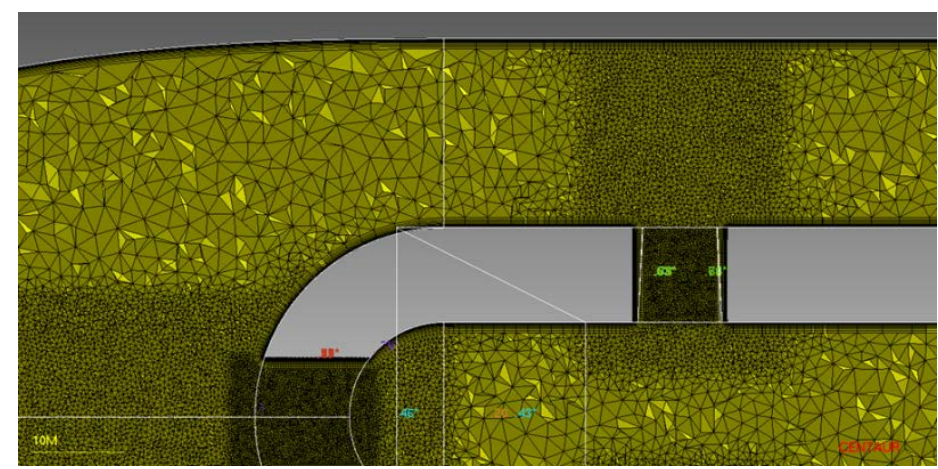

Figure 6 . Mesh overview for ZDES modelling 


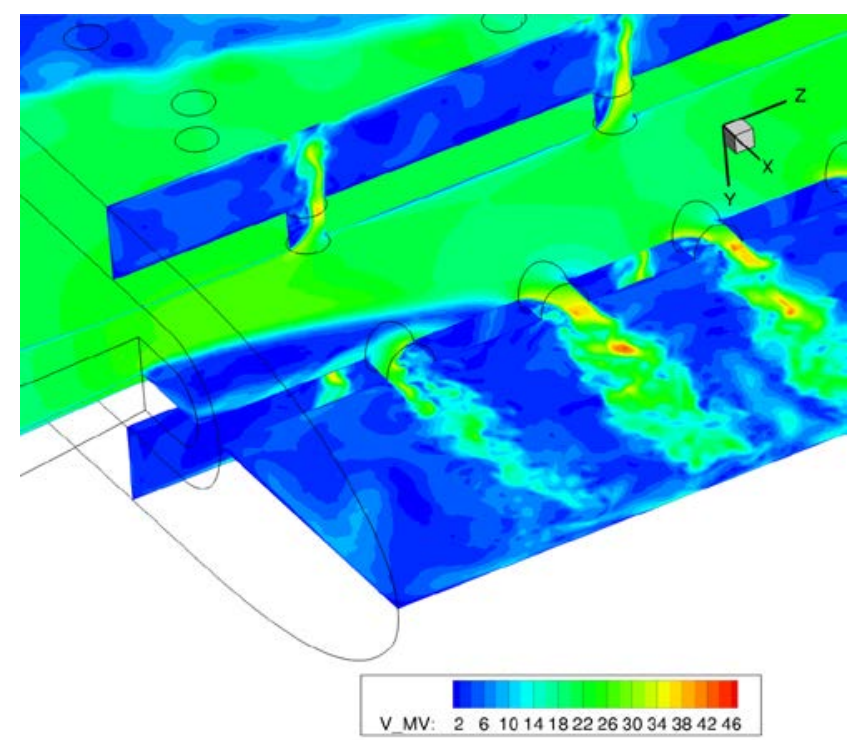

Figure 7 : ZDES Velocity magnitude overview 


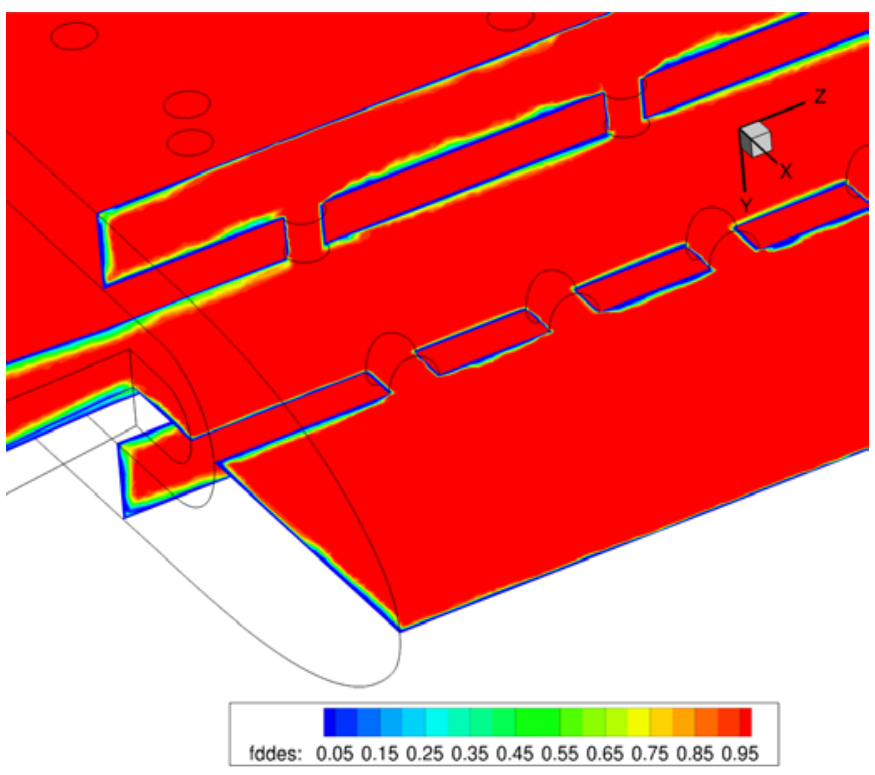

Figure $8 . F_{\text {ddes }}$ function distribution 
VMV: 012345678910111213141516171819202122

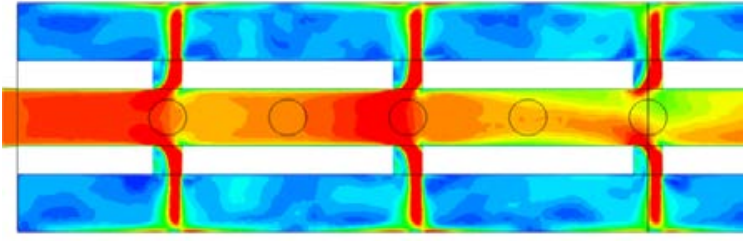

Figure 9 : Velocity magnitude in a slice going through row 2 (CEDRE k- $\omega$ SST) 


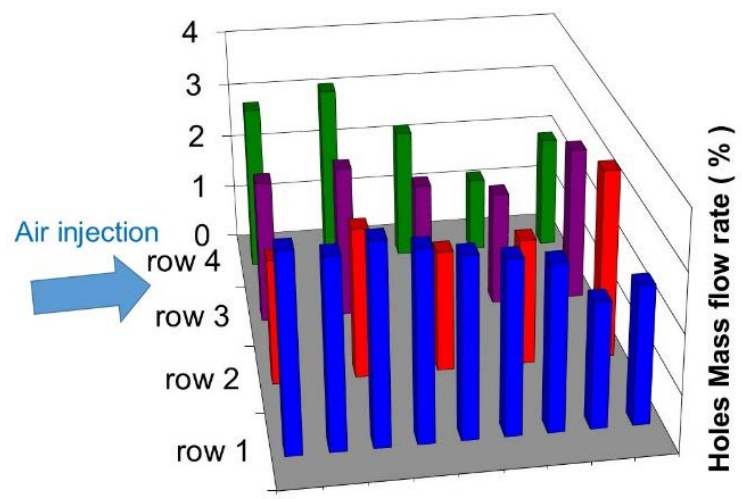

Figure 10 . Mass flow rates 

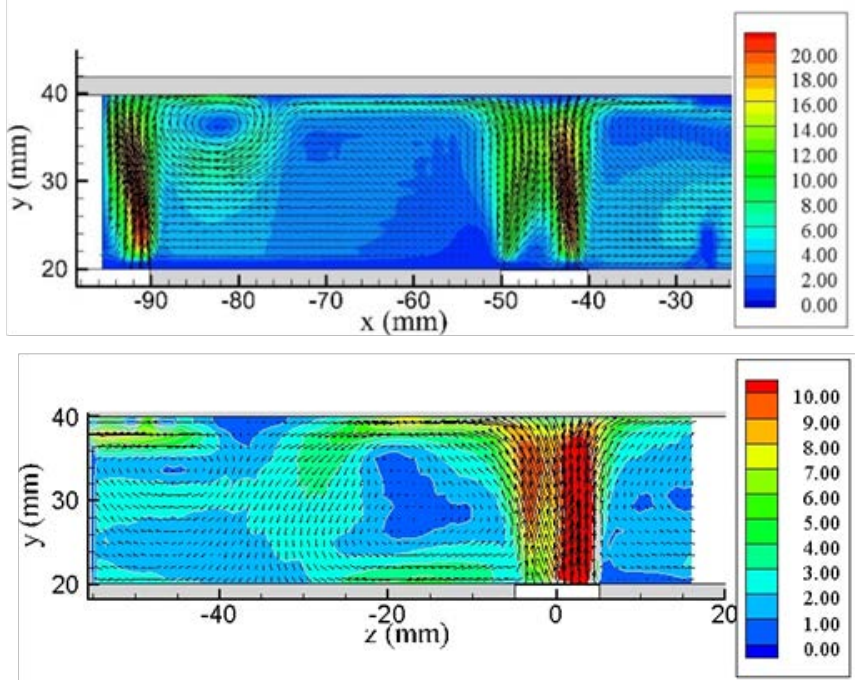

Figure 11 . Velocity Magnitude Distribution, PIV (top: plane (C), bottom plane (D)) 

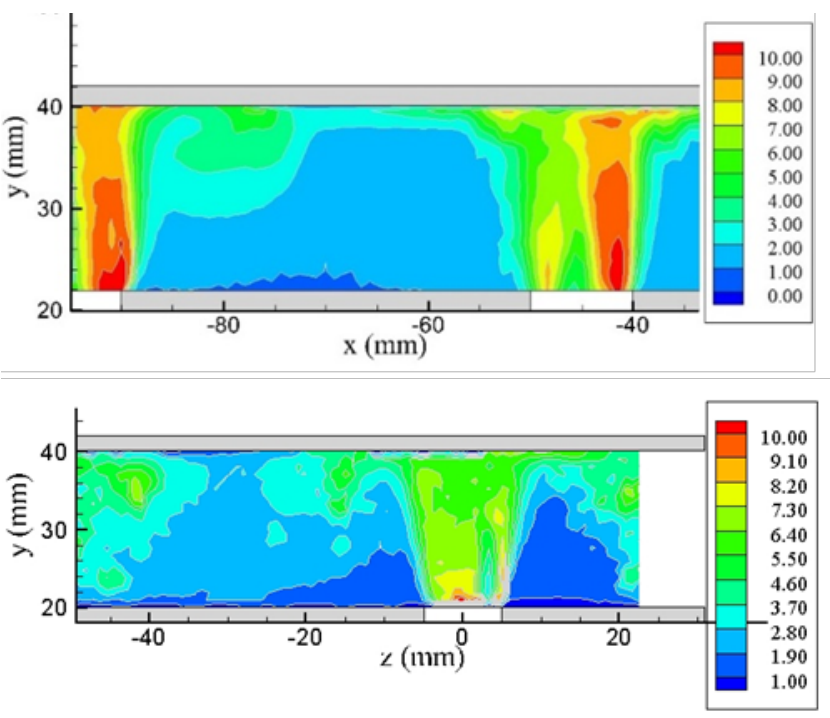

Figure 12 . Velocity RMS Distribution, PIV (top : plane (C), bottom plane (D)) 

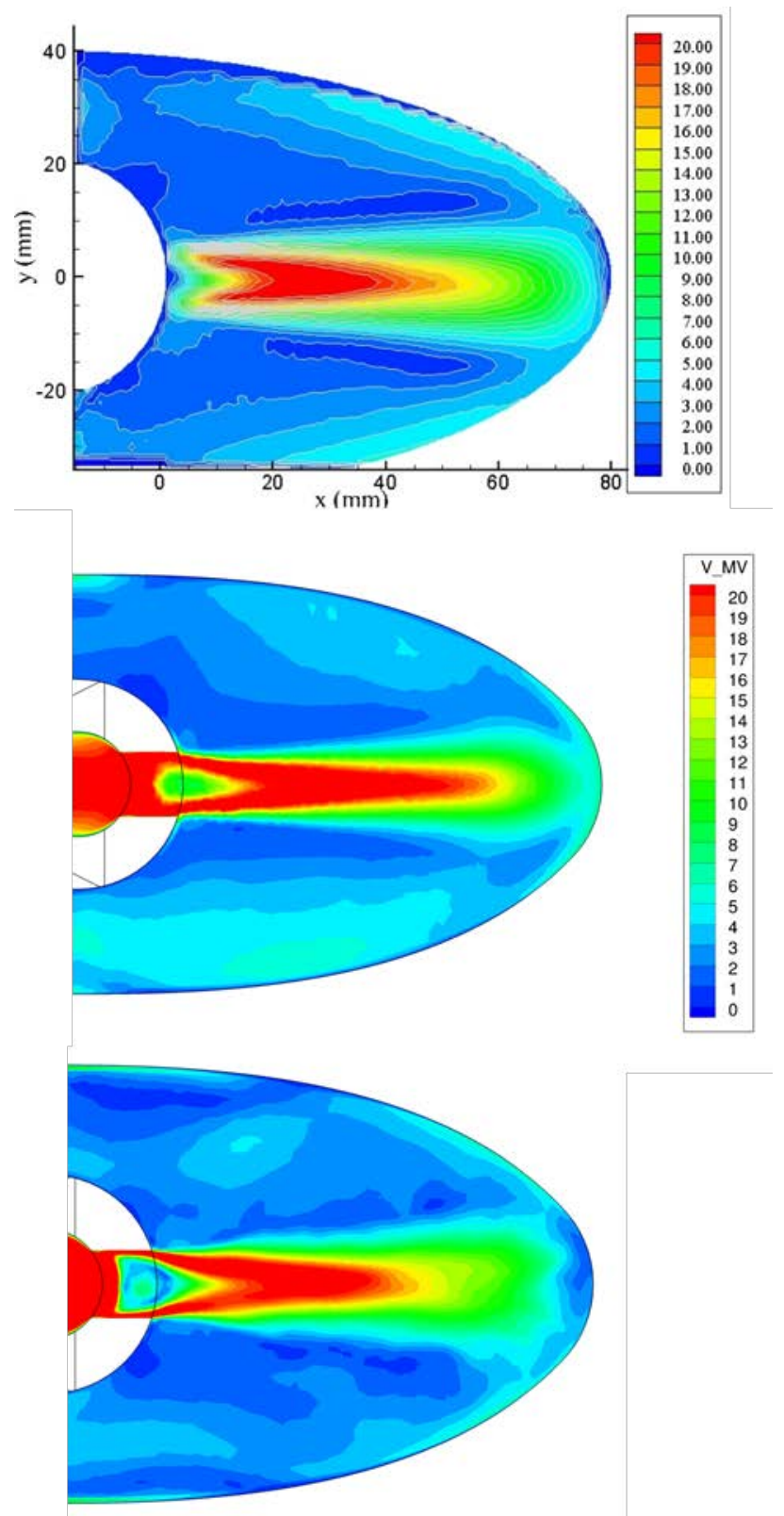

Figure 13. Velocity Magnitude Distribution, plane (A) (top : PIV, middle CEDRE RANS, bottom CEDRE, ZDES ) 

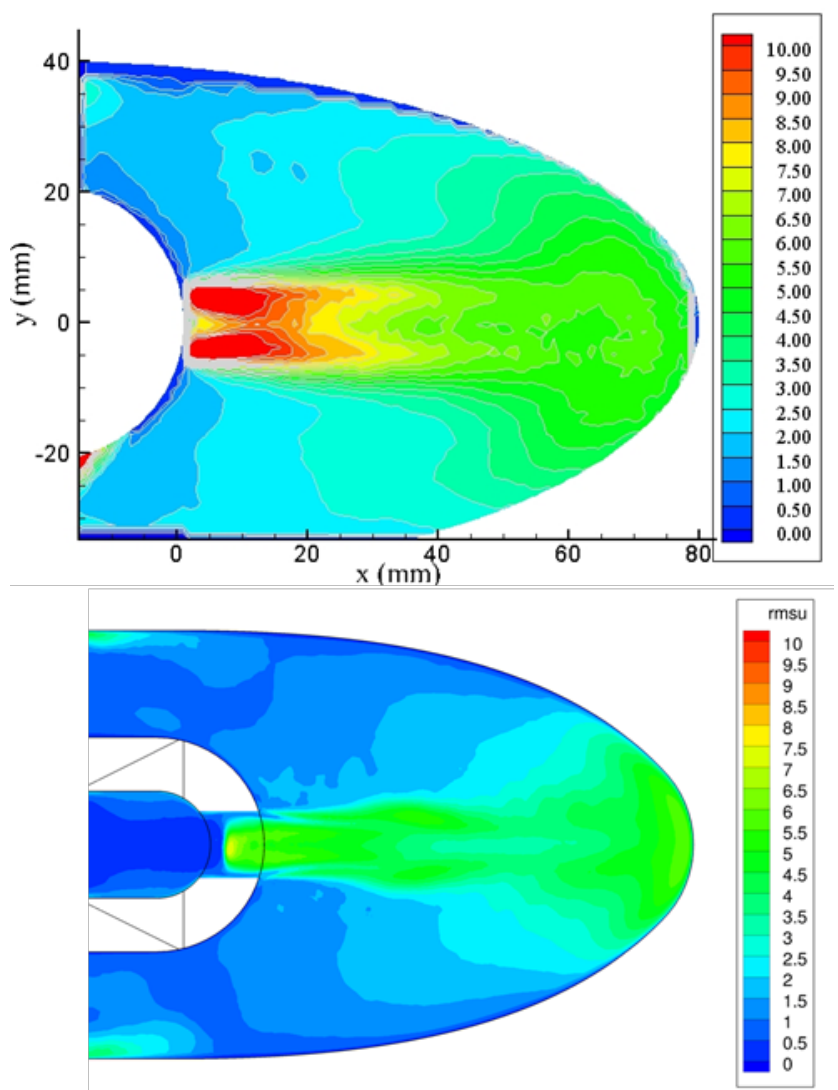

Figure 14 . Axial velocity RMS Distribution, plane (A) (top : PIV, bottom CEDRE k- $\omega$ SST) 


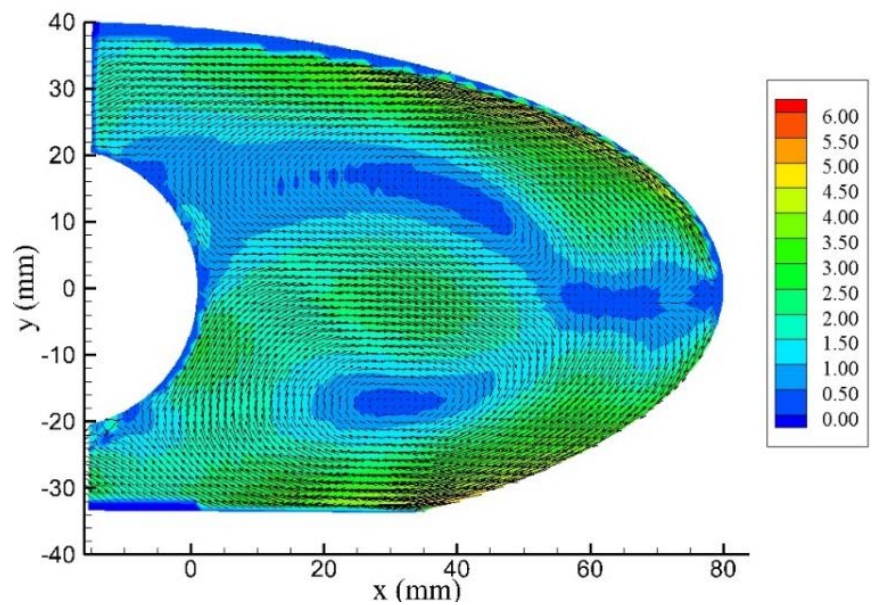

Figure 15 . Velocity Magnitude Distribution, plane (B), PIV 


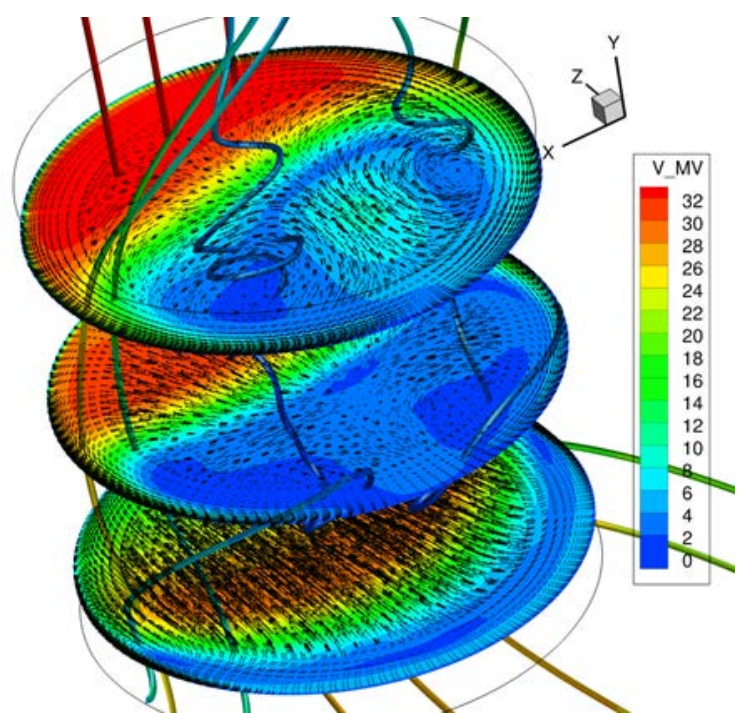

Figure 16 . Velocity Distribution/Streamlines colored by velocity inside the hole 

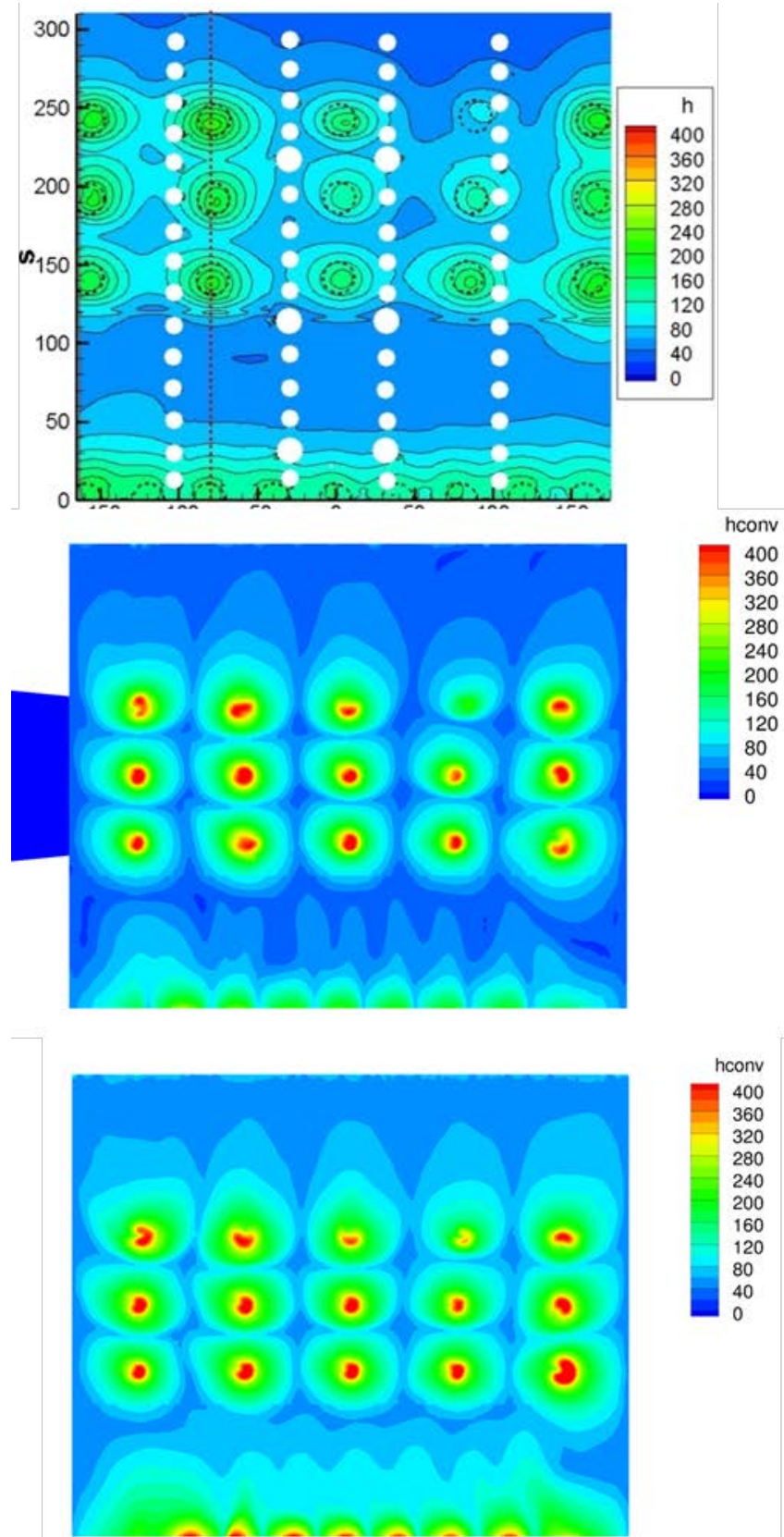

Figure 17 . Heat transfer coefficient distribution (top: Exp., Middle, k- $\omega$ SST; bottom Billard-Laurence) 


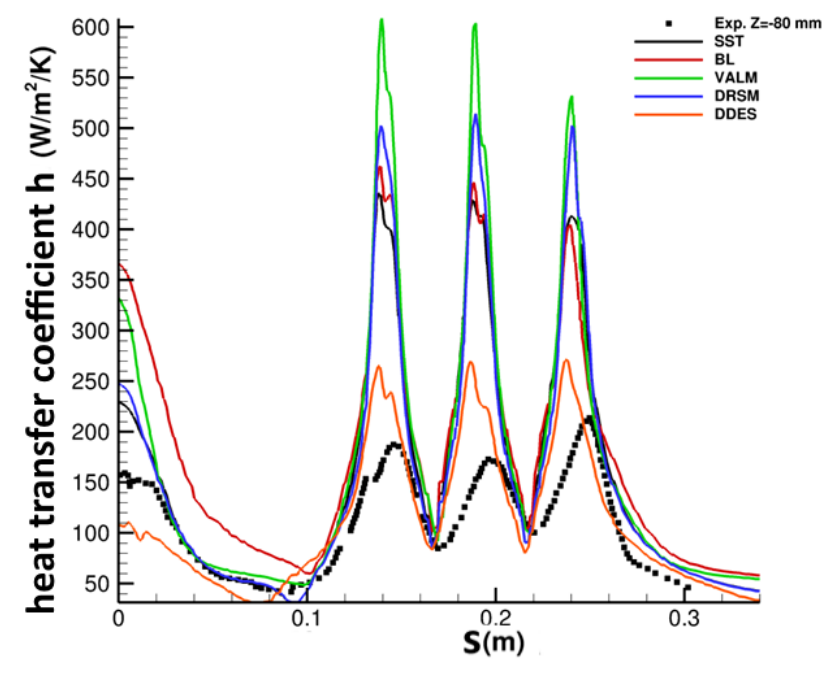

Figure 18. Heat transfer coefficient profile along the second column of holes 